\title{
IJTARP
}

$12(1), 35-41$

International Journal of Transactional Analysis

Research \& Practice

\section{Injunctions and Motivation in Human Growth from the Perspective of Triology}

\author{
(C) 2021 Ranjith MR
}

\begin{abstract}
The author combines Kandathil's (1978) approach of Triology that combines I, You and Goal, and how these are connected in terms of Identity, Rationality and Relationship, with transactional analysis theories about injunctions and permissions. The result is illustrated as an extended GK Frame to provide a model for analysing how childhood decisions are preventing the current growth of clients. Injunctions and injunctive messages are both considered, and permissions are described in terms of love, hope and trust. A significant link is also made with Maslow's Hierarchy of Needs and this in turn prompts some initial considerations about the nature of spiritual growth. A brief case study is included to demonstrate how the resulting framework can assist with analysis that can be shared with clients.
\end{abstract}

\section{Key Words}

injunction, injunctive messages, motivation, triology, identity, relationship, rationality, hierarchy of needs, GK frame, permission

\section{Introduction}

Human growth is a complicated process. Many theories have attempted to explain the true nature of human growth. Psychology, philosophy, and spirituality have joined hands in their attempt to present a satisfactory explanation of this aspect. Humanistic psychologists assume that the fundamental nature of human beings is good. But this assumption is objectionable in the light of real-life observations. There is a lot of unrest in society, and many people are unhappy. At the global level, piling up weapons of mass destruction, unprecedented levels of pollution, global warming, and many other man-made problems are causing a threat to the very existence of the human race like the sword of Damocles. If the fundamental nature of human beings is good, why do people think that they are not OK? What is it that disrupts the natural flow of human growth? This is the problem discussed in this article.
Three different theoretical approaches are compared here to deal with the subject from a holistic perspective: Maslow's (1954) hierarchy of needs; injunctions (Goulding and Goulding 1979) and injunctive messages (Mc Neel 2010); and GK Frame (Kandathil 1978; Sidharthan 2016). Brief descriptions of these theories are provided in the article which will enable the readers to make meaningful conclusions about the subject.

Intuition is a faculty that often gives an initial impetus to any scientific exploration. Subjective experiences of people need to be studied while exploring new avenues of knowledge, especially while dealing with depth psychology. The definition of human growth is highly subjective, so the personal experiences of people are given due weightage in the methodological approach of this article. One case study to vouch for the practical usability of the topic is also discussed.

\section{Triology}

Triology is a meta-theory propounded by Fr. George Kandathil SJ (1978). Triology means a theory of three. I, You, and Goal are its cornerstones. Triology essentially attempts to answer the question: Who is a human being? GK Frame represents the central concept of Triology, which furnishes a philosophical structural analysis of human beings. Triology assumes every human being is defined by three different but interrelated aspects: relationships, rationality and identity. GK Frame, a name applied later by Sidharthan (2016) is illustrated as an equilateral triangle formed with three vertices marked as I for Individual, $U$ for You or others, and $G$ for goal. Points $I$ and $U$ form the base of the triangle. and $G$ is at the apex. The sides of the triangle are Relationship (IU), Identity (IG), and Rationality (UG).

- Relationship: The first relationship a person has in this world is with their primary caretaker, who is often their mother. A problem in the relationship with the primary caretaker at this stage can cause lifelong relationship problems. 
Human existence is essentially a matter of interdependence. No one can survive all alone; each one needs to have a relationship with others. In the perspective of Indian Psychology these 'others' include not only other human beings but also all other organic and inorganic forms as well. At this point of expanded awareness, $U$ shall grow from mere You to the Universe. Human beings depend on others for food and other material needs; also for procreation and recreation, so the relationship is fundamental to human existence.

- Identity: When a person attains their goal, they tend to identify themself with their achievement. When somebody says that they are an Olympian, they are identifying themself with an achieved goal. Thus, a self-image is born, which covers up the real nature of the individual. Personality is a mask that covers up the true essence of the individual. Many of the psychological issues are arising from the confusion of self-image and identity. What determines a person's true identity is the ultimate Source of their origin, not the physical achievement or its absence. This is in alignment with the philosophical assumption of TA. People are OK. In other words, self-image is different from identity. At this, philosophical level $G$ will grow from a mere Goal to God (whatever you believe this to be).

- Rationality: The Greek Philosopher Aristotle said that 'man' is a rational animal. Rationality is the quality that distinguishes human beings from other animals. When a person can understand how others $(U)$ help them to reach their goal $(G)$ the individual is thinking rationally. Here the $U$ stands for not only human beings but also the world of inanimate matter in the environment.

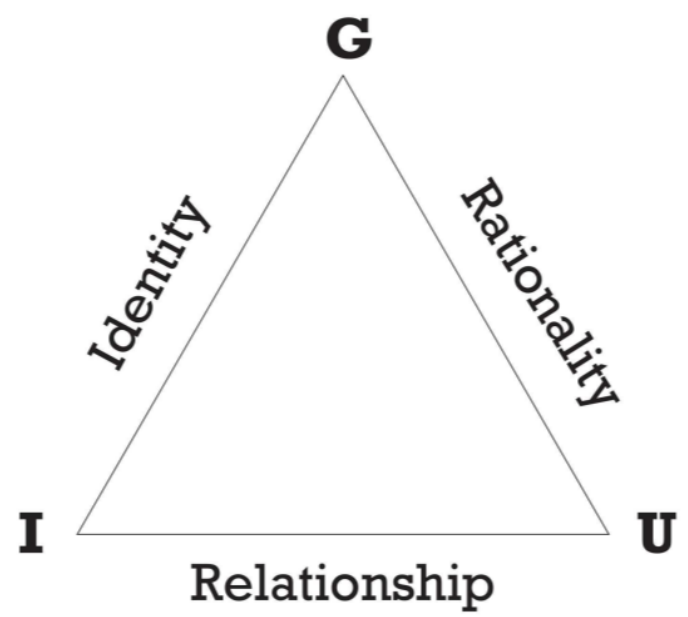

Figure 1: GK Frame (Kandathil, 1978, P.63)
When one can learn from others' and our own mistakes, we are thinking rationally. Rationality helps us to survive in the world and guides us to develop the talents we are born with.

It is possible to form many other analytical frames for understanding human problems and also their solutions from the GK frame. It has got the flexibility and the strength to understand various human problems resulting from irrational behaviours, wrong ways of relating and faulty identity. Also, it can build a bridge between psychology and spirituality. Expanding on the vast possibility of the GK frame is beyond the scope of this article. However, GK Frame is the basic structure onto which the other theories mentioned in this article are applied.

\section{Injunctions, Injunctive Messages and Permissions}

Berne (1972) wrote that "Recently, R.D. Laing, the British psychiatrist, has described in a radio broadcast a view of life which is amazingly similar, even in its terminology, to the theory discussed in this book. For example, he uses the word "injunction" for strong parental programming. Since, at this writing, he has not yet published these ideas.... " (p.59). Berne referenced the term "injunction" to Steiner (1966) and described it as an "unfair negative command... script injunction or stopper... given by a Controlling Parent or a crazy Child ego state." (p.107).

Goulding and Goulding (1979) defined an injunction as "messages from the Child Ego State of Parents, given out of the parents' pains, unhappiness, anxiety, disappointment, anger, frustration, secret desires." (p.9). Goulding and Goulding also settled on a list of twelve common injunctions. McNeel (2010) published a list of twenty-five injunctive messages and categorised them into 5 classes: Survival, Attachment, Security, Identity and Competence. He defined injunctive messages as "messages emanating from parental figures, often outside their awareness, that are negative in content, often delivered in a context of prohibition, and defeating to the natural life urges of existence, attachment, identity, competence and security." (p.159).

Injunctions/injunctive messages are a hindrance to the natural growth process as they act like the fabled 'curse' that turned the prince into a frog. We might also think of injunctions/injunctive messages as like the chain on an elephant's leg - arresting its freedom and making it forget its strength. Injunctions play a major role in turning princes and princesses into 'frogs'. They are received at a very young age, and it is through the coloured glasses of these that the child continues to perceive the world. That is how they become obstruct- 
ions to natural growth. It is an energy source from within to stop activities that can encourage life. In general, we can call it an evil force. The word 'live' spelt backwards is 'evil' - evil is the opposition to live life the way it should be lived. "Evil, then, for the moment, is that force, residing either inside or outside of human beings, that seeks to kill life or liveliness. And goodness is its opposite. Goodness is that which promotes life and liveliness." (Peck 1983 p.42-43).

The 'goodness' available to counter the effects of injunctive messages are permissions. Berne (1972) wrote that "Permissions are the chief therapeutic instrument of the script analyst because they offer the only chance for an outsider to free the patient from the curses laid on him by his parents." (p.151). According to Drego (1996), "permission is a sentence that gives you life and energy together with a good warm feeling."(p.9).

Finally, Crossman (1966) defined permission as "a particular transaction that occurs between therapist and patient at a particular point in therapy, whereby the therapist effects a change in the direction of the patient's behaviour or attitude which before that time would have seemed either impossible or untenable." (p.142). Crossman also stressed the significance of providing protection alongside any permissions conveyed to clients.

\section{Maslow's Hierarchy of Needs}

"'Human life will never be understood unless its highest aspirations are taken into account. Growth, self-actualization, striving toward health, the quest for identity, and autonomy". (Maslow 1954 p.xii). Maslow proposed that human motivation is based on needs. He listed some of the needs of human beings from his clinical experiences and other known facts at the time of publication, showing basic human needs as:

- Biological and physiological needs - When the physiological homeostasis is disturbed the organism feels the need in the form of hunger, thirst, etc. Air, water, food, sex, and sleep are basic biological requirements for survival. Also, there is a need for excretion of waste from the body. Maslow says, "A person who is lacking food, safety, love, and esteem would most probably hunger for food more strongly than for anything else."(1954, p.37].

- Safety needs - Need for security, stability, dependency, protection, freedom from fear, from anxiety and chaos, need for structure, order, law, etc. If the safety needs are not fulfilled the receptors, effectors, and intellect of the organism will be functioning as safety-seeking tools.

- Love and belonging needs - "If both physiological and safety needs are fairly well gratified there will emerge the love and affection and belongings need". (1954 p 43). Human organisms will actively seek relationships, friendship, intimacy, trust, and acceptance, etc.

- Esteem needs - Esteem needs include the need for achievement, mastery, independence, status, prestige, respect, and recognition from others, etc. The need for a high evaluation of self and the need for self-respect and self-esteem is in this class of need.

- Self-actualization needs - Realising one's potential, seeking personal growth and peak experiences. A process of growing to the fullest possibility of the individual.

\section{Combining Theories}

\section{GK Frame and Injunctions}

When the classification of injunctions is interpolated with the basic diagrams of the GK Frame, some interesting insights about human nature emerged. For survival, human beings need to interact with others on a continuous basis. Survival, attachment and security injunctions can be logically placed on the relationship side of the GK Frame. It is interesting to see most of the injunctions fall in this area of human activity. Rationality is the indispensable requirement for achieving competence. So the competence injunctions are aligned in the rationality side of the frame. Achieved goals are attributed as the individual's identity by society and by self; so the identity injunction can be placed on the identity side of the frame. (Figure 2).

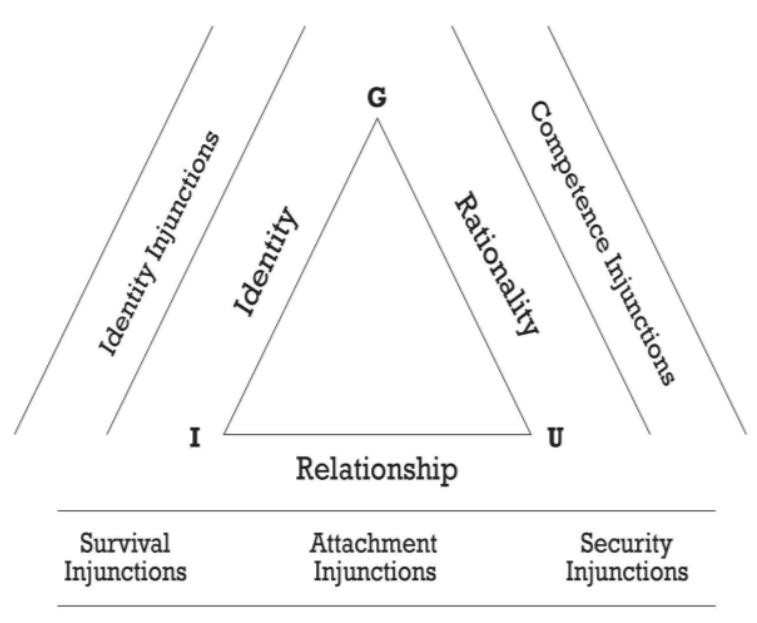

Figure 2: GK Frame with Relationship Injunctions

When this combination is used in the context of counselling, the first step is to identify to which side of the GK Frame the problem belongs. Then the counsellor can look for the presence of corresponding 
injunctions. After identifying the problem, it is easy to define it, make a contract and enter into problemsolving steps. In short, this can be used as a diagnosing tool.

Problems on one side of the GK Frame could cause problems on the other sides. For example, teenagers while facing identity issues may have strained relationships. At the same time, the competence level also may suffer. By analysing more and more injunctions/GK combinations; developmental crises can be predicted with more accuracy. A practical method to approach the core issue can be devised by working on it from the injunction or injunctive messages.

Further extending this triangle we can add corresponding injunctions alongside corresponding sections. (Figure 3). As seen from Figure 3, most of the human problems lie in the relationship side of GK Frame.

GK Frame and Maslow's Hierarchy

Although Maslow never used a pyramid diagram, this diagrammatic representation has often been used and helps to visualise the theory. Figure 4 suggests some blocks that might happen in each level:

- A reverse engineering assumption indicates that a person with more survival injunctions may be affected by somatic symptoms, because blockage is on bodily needs.
- Some behaviours, like reluctance to spend money or other resources, could be related to unfulfilled safety needs.

- People with attachment injunctions could have trouble with intimate relations and friendships. The wrong way of relating to others is one of the major reasons for conflicts in families.

- People who have trouble in the rationality side of the GK frame would have problems in academic and other competency levels. Rather than looking at improving rationality, it would be more effective to work with competence injunctions, by providing necessary permissions in that area.

- People with Identity injunctions could have difficulty in truly identifying who they are, and may have troubles with actualisation of personal potential. This area is also closely related with spiritual development of the individual.

Usefulness of combining theories

Motivation is like an upward pulling force that accelerates human growth, A natural rule of growth is to self-actualise and attain full growth potential, which is well explained in Maslow's theory. On the other hand, injunctions are the stopping messages to the natural growth of a child, provided by its parents and society. The messages are internalised as the child grows, so the injunction works as a limiting force from within. Permission removes the blocks caused by injunctions.

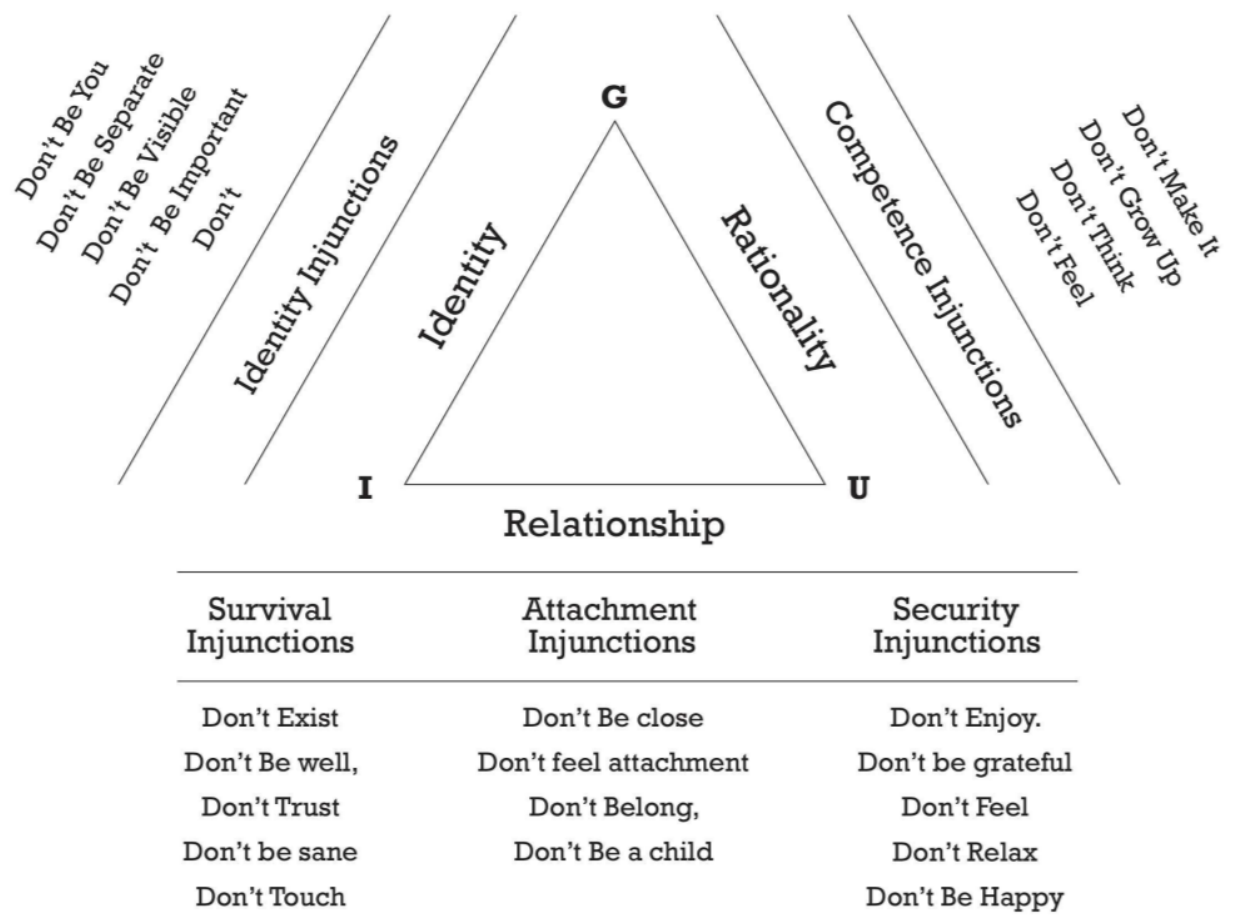

Figure 3: GK Frame with Identity and Competence Injunctions 


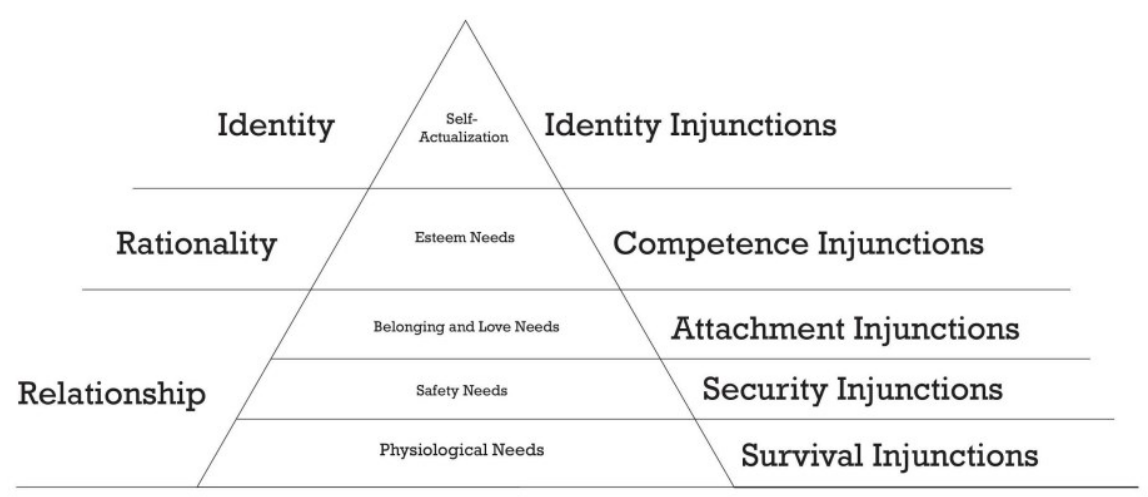

Figure 4: Maslow's Hierarchy and Injunctions

Maslow pointed out that individuals may move onto higher levels without satisfying lower levels, such as an artist self-actualising to paint even though they lack food. We might also consider why people do not progress to areas of higher needs even after fulfilling all their basic needs. For example, a person who worked for 30 years abroad and earned sufficient money but is still postponing retirement and being together with family. Sometimes, people reaching the higher areas of the triangle happen to have great falls in their lives, such as a nearly self-actualised teacher sexually abusing a student. It is difficult to find answers to such human behaviours from the hierarchy of levels. The combination of injunction theory and GK Frame can provide a better framework to understand, explain, predict, and change some of these complex human behaviours.

\section{A Case Study Example}

Motivations, injunctions and permissions are subjective. The above-mentioned combinations of theoretical frameworks can be useful in objectively evaluating these concepts. The following elements of a case study are provided to illustrate these concepts and their practical application.

Client: Tresa a 26-year-old unmarried women research scholar was having a sleepwalking problem. The problem was more frequent when she was stressed. Also, she was not able to clear some of the examinations even after a sufficient amount of hard work. She was missing the target by very small margins on every attempt.

The Drego Injunction Scale (Drego 1996) was used and Don't think, Don't make it, and Don't feel were the top three injunctions. These scores were in agreement with the reported stories by the client. Don't think and Don't make it injunctions are falling on the rationality side of the GK frame and Don't feel injunction on the relationship side. Insights from the injunction test helped further exploration into the repeated behavioural pattern of the client.

We explored more about her relationship patterns from the perspective of the GK Frame, which is of course illustrating the basic concepts of triology. She reported having a good relationship with her mother. However, she added, "Mother was good at studies as a child, but she could not go beyond primary school". When Tresa was six years old, her sister was born and after this, she felt "neglected" by her mother. Tresa was sent away to stay at her mother's sister's home for schooling. Throughout her education period she was away from home and later staying in hostels.

Tresa reported that she always has some or other kind of "dependent" relationships. During her graduation and postgraduation courses, she had relationships with three different boyfriends, one after the other. She said she used to leave each one before they could leave her. Tresa said she suffered more sleepwalking sessions during the time of breakups with her boyfriends. Also, she realised these relationships affected her performance in examinations. These findings are in line with the information that Tresa has Don't feel, a security injunction that lies on the relationship side of the GK Frame. Tresa also reported that during vacations she used to leave home to go back to the hostel one day earlier than it was required for some unknown reasons. Both statements indicate some issues with the security part of Tresa's relationships.

One of her childhood memories is that after the baby sister's birth, Tresa was made to sleep alone in a small cot which was put near to the cot where her mother, father, and baby were sleeping. She said her cot was so small that her father could not sleep on it. When she felt afraid, her father used to extend his hand towards Tresa so that she can hold it and sleep. One night Tresa felt lonely and frightened, and she cried. 
Everyone was sleeping, so she took her father's hand and placed it on her cheek, hoping that he would feel her tears, but he was sleeping and did not respond to Tresa's sorrow. She felt angry and sad and threw his hand away. While narrating this incident, she was sobbing like a child. Tresa realised this was the pattern she followed when she rejects boyfriends before they can reject her. Also, she remembered the frightening dreams which deprived her of sleep.

Further exploration into the childhood of the client revealed new insights about her relationship with her mother. Her mother used to encourage Tresa to study well - however, she remembered the mother's disappointment about not able to complete her own studies. This might be the reason for the client receiving the Don't Make it Injunction. Getting involved in distracting relationships during examinations could have been her way to obey this injunction.

The systematic approach of exploring one side of the GK frame at a time made it easy to collect more information about the non-verbal and forgotten events of the client's childhood. In Tresa's case a session focused on her relationship with her mother revealed a lot of insights to her unconscious patterns.

The use of GK Frame and injunction scales together could dig deeper into the repressed areas of the human mind and help to reveal long-forgotten unpleasant childhood experiences in a focused manner. These insights will help clients to help themself effectively. For a therapist, these are precious guidelines that can help in planning the therapy procedures.

\section{Permission}

Finally, there are three attributes we can show on the GK Frame that can make the therapist more potent in providing permission, as shown in Figure 5:

- Love is a great force that connects the permission giver and taker. The relationship that is the base of the GK Frame is an important aspect for the permission to be effective. Unconditional love is the purest form of relationship. Unconditional acceptance by the therapist helps clients to rework the problem areas of their childhood relationships. Peck (1983) defined love as "The will to extend oneself for the purpose of nurturing oneself or another's spiritual growth". (p.119).

- Hope given through permission is effective in clearing distorted thought processes that are hampering rationality. The hope may be seen as a suggestion towards goal completion. Hope will show psychological images of the goal achieved, which will induce calmness in the person that will enable them to think clearly and act peacefully.
- Trust is another aspect that helps permission to work well. When unconditional trust is extended, it works on the identity of the person. The person realises their self-worth. Also, it helps resolve identity confusion when they realise that another person simply believes them.

Love is in the relationship side of GK Frame. Hope is pointing to the goal and rationality side. Trust is all about believing the capacity of the individual and it lies on the identity side of the GK Frame. Permission given with Love, Hope and Trust is more effective.

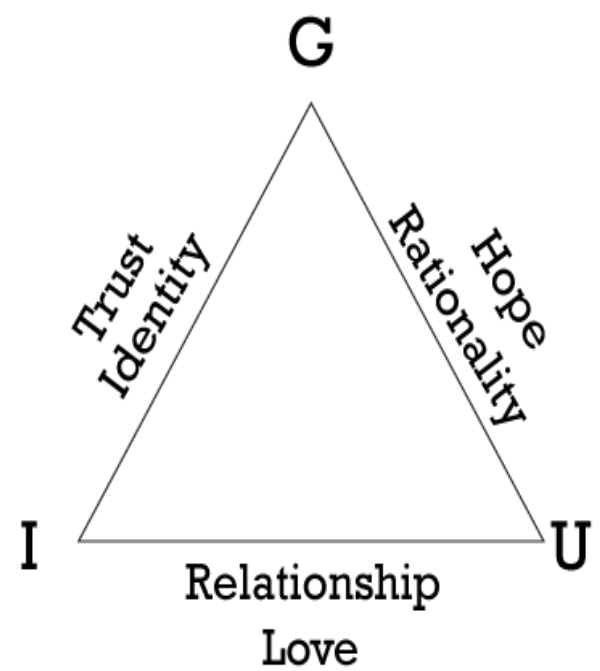

Figure 5: GK Frame and Permissions

Incidentally, spirituality also highlights the importance of love, hope, and trust in the evolution of people into their higher selves. Careful scrutiny may reveal that the GK Frame is a theoretical framework that connects psychology with spirituality. All world religions are instituted with the purpose of improving spiritual growth. The violence in the name of religion begins when the intentions go wrong. When it has wrong notions about love, a religion divorces itself from spirituality, and that is where religious violence begins. This fact is well recorded in the history of religions throughout the world.

\section{Conclusion}

The combination of the GK frame with injunctions/injunctive messages and Maslow's hierarchy of needs can be used as a model for both practitioner and client to investigate how childhood experiences, whether related to parents or the culture, have led to current difficulties for the client. Permissions can be more appropriately crafted and targeted to specific client needs.

It seems to me also that these models connect the concepts of TA with spirituality. Explorations on the 
identity side of the GK frame can lead to understanding about spiritual evolution of the person.

Although the material presented in this article has not been researched, and there are only brief details of using the model in analysis of a single case study, I hope that enough information has been included so that other practitioners may begin to use these ideas. I look forward to receiving information from my colleagues as they apply these ideas.

Ranjith is currently a Bernian Transactional Analyst (with the Institute for Counselling and Transactional Analysis www.ictaindia.org) and expects to continue training to become a Master Transactional Analyst. He can be contacted on mr.ranjth.mr@gmail.com

\section{References}

Berne, E. (1972). What Do You Say After You Say Hello? Grove Press.

Claude, S. (1966). Counterscript. Transactional Analysis Bulletin, 18, 133-135.
Crossman, P. (1966). Permission and Protection. Transactional Analysis Bulletin, 5(19), 152-154.

Drego, P. (1996). Cultural Parent Oppression and Regeneration. Transactional Analysis Journal, 26(1), 58-77. https://doi.org/10.1177/036215379602600111

Goulding R., \& Goulding, M. (1979). Changing Lives through Redecision Therapy. Grove Press Inc.

Kandathil, F. G. (1978). TA and Triology for You and Me. ICTA.

Maslow, A. H. (1954). Personality. Harper \& Row.

McNeel, J. R. (2010). Understanding the Power of Injunctive Messages and How They Are Resolved in Redecision Therapy. Transactional Analysis Journal, 40(2), 159-169.

https://doi.org/10.1177/036215371004000211

Peck, M. S. (1983). People of the lies. Simon \& Schuster.

Sidharthan, S. (2016). Prelude to Triology. Unpublished document used as course handout. 